\title{
Anne Schjoldager with Henrik Gottlieb \& Ida Klitgård 2008. Understanding Transla- tion. Aarhus: Academica Aarhus, 312 pages. ISBN 978-87-7675-510-2
}

Understanding Translation is a textbook for students of translation and languages, and has been developed out of material created by Anne Schjoldager for her MA classes in translation and interpreting. Extra chapters are included from Henrik Gottlieb, on multidimensional translation and screen translation, and by Ida Klitgård on literary translation.

Writing an introductory book of this type is fraught for all sorts of reasons, notably the questions of what to include and what to omit, how much theory (and which theory) should predominate, whether it should be built around examples, and, if so, in which language(s), whether exercises should feature, etc. Understanding Translation sets its own path through the subject and is a welcome addition, written in English for a very specific market in Denmark.

To get us started, let's list the chapters: 1. Needing theory; 2. Defining translation; 3. Categorising translation; 4. Multidimensional translation; 5. Macrostrategies; 6. Microstrategies; 7. Professional ethics; 8. An overview of translation studies; 9. The skopos theory; 10. Interpreting; 11. Screen translation; 12. Literary translation.

The brief introduction (p. 11) indicates that Chapters 1 to 9 represent 'a conceptual framework for the theory and practice of translation in general', with the last three chapters dealing with the peculiarities of distinct modes of translation and interpreting. The 'theory and practice' question is central to the book, starting with a justification for the study of theory (pp. 14-15). Each chapter then adopts a format of accessible theoretical survey with bullet-pointed lists illustrated by well-chosen translation examples, finished off by 'points for discussion' based on Danish-centred scenarios. This demonstrates the focus of the book: it is an introductory textbook for Danish students of translation/interpreting and of languages, and the examples are almost all of translation between Danish and English, often with back translations for non-Danish speakers. The style of most chapters is quite informal, and the student readership is addressed directly and in opposition to the informed authors and research community ('we intend to give you an in-depth understanding of the phenomenon of translation...' p. 13). While this cuts through the theoretical jargon and explains in refreshingly plain language, I felt such a distance between the informed and the learners was overdone at times ('Here is a list of anthologies... that would be a good starting point for you as a newcomer to our field' p. 147) and puts unnecessary constraints on the target audience which could well include professional translators and students with some experience in translation; it also lowers the expectations of the students, who, through their background and own work, are often capable of bringing fresh and illuminating insights.

The focus is specifically on interlingual translation, the definition of which may, however, be too broad and a little shaky for some tastes: 'A translation is a text that expresses what another text has expressed in another language' (p. 19). It is mainly concerned with professional and non-literary translation practice, and there is a good introduction to and application of some translation theories to actual practical scenarios: House's overt and covert translation (pp. 32-35); Snell-Hornby's integrated translation categories (p. 36); various 'dichotomies' of source-and target-oriented translation macrostrategies (briefly alluding to Nida, Newmark, Toury, Venuti, etc. in Chapter 5); an innovative blend of Vinay \& Darbelnet and Delabastita for the microstrategies (Chapter 6); more reliance on Chesterman for the norms and ethics Chapter 7; and skopos and action theory and the functionalists, most notably Holz Mänttäri and Nord, in Chapter 9.

A couple of examples of probing 'points for discussion' from the 'Professional ethics' chapter (p. 129) may serve to illustrate the wealth of potential for exploitation in class. One relates to the interpreter's role:

You are acting as a freelance interpreter in a business negotiation between a Danish company and an American company. You have been hired by the Americans. The parties have separated to discuss some details with their backup people. You are off duty but happen to overhear what the Danes are planning 
to do. Afterwards the Americans ask you: “Can you tell us what they’re planning?” Could you?

The other to what is an 'ethical' translation strategy:

You are a Danish author of childrens' books. You are approached by a Danish publishing company and asked to translate an American comic book for children into Danish. Which macrostrategy would you choose, do you think?

Both demand decision and argumentation on what the student considers to be justified conduct in these very specific and fully realistic scenarios.

As indicated above, the wider question of translator strategies is dealt with in Chapters 5 and 6, first as 'macrostrategies' (basically centring on 'source-text oriented' vs 'target-text oriented') and then as 'microstrategies' (reworked by Schjoldager as calque, direct translation, oblique translation, explicitation, paraphrase, condensation, adaptation, addition, substitution, deletion and permutation). Chapter 9 is then devoted to skopos theory, translational action theory and Nord's model of translation problems and text analysis. Students are therefore provided with a good grounding for their practical needs and for reflecting on and taking decisions in a range of different translation scenarios. Some of the interlinked 'points for discussion' in Chapter 9 (pp. 182-186) present a complex real-life scenario, the translation of Danish folksongs and hymns and its reception, with questions about translator role, brief, skopos, and both macro- and micro-strategies employed.

The practical applications of theories work very well in the book, and the authors are to be congratulated. What is perhaps a little less successful is the combination with those chapters that move more fully into the area of broader translation studies. Chapter 8 (pp. 133-150), for example, is the curiously labelled 'Overview of translation studies', as if what has been presented up to this point ('understanding the phenomenon of translation') is something apart from the field. This chapter is a lightning run-through of some of the origins of European writing on translation from Roman times to the present (following the eight stages discussed by Chesterman), and of the establishment of the discipline from James Holmes's early work on the name and nature of translation studies. Here, I would have liked to see more discussion on the applicability of Holmes's 'map' of the discipline. For example, many of the 'points for discussion' (pp. 148-150) specifically relate to Holmes's classification, a simplified version of which is presented. A question asking students to relate specific scenarios to this map seems to be very taxing without considerable input from the tutor. Nevertheless, there is a useful, though brief, discussion of some present trends in translation studies including descriptivism, contextualisation and changes in the profession. Once again, the focus is very much on practical factors and applications; work from a cultural studies perspective, postcolonial or feminist translation theories, hermeneutics, etc., and even recent sociological advances in translation studies, do not get a look in. As a counterpoint, Chapter 10 deals with interpreting, again rather briefly (pp. 187-202). It adopts the assumption that interpreters and other translators are expected to act as 'facilitators of communication' (p. 193)

The other three theoretical chapters are written by the other authors. They are solid work, but they could perhaps be more fully integrated into the whole. Thus, Henrik Gottlieb contributes two very interesting and detailed chapters: Chapter 4 on multidimensional translation and Chapter 11 on screen translation. In the first of these he discusses different forms of translation and presents his typology of 33 types of 'intersemiotic translation', presented (in the table on pages 43 and in the following discussion) according to the target text semiotics (diasemiotic [different channel compared to the original], supersemiotic [more channels] and hyposemiotic [fewer channels]) and, along the other axis, 'conventionalized translation' or 'adaptational translation' (both subcategorized according to nonverbal, deverbalizing and verbalizing). Another table (p. 44) deals with 'intrasemiotic translation' (i.e. where the same sign system is used). This is a good theoretical debate that hugely expands Roman Jakobson's well-known classification of three translation types and overtly challenges entrenched notions of what translation is. Yet at the same time, it is rather out of sync with the rest of the book. It is far more theoretical, the points for discussion are very brief and it also to some extent challenges some of the concepts in the other chapters, such as the 
restricted view of translation (p.19, see above), the use of multimedia (rather understated in other chapters) and whether translators do really work systematically and adopt macrostrategies.

Gottlieb’s other chapter (pp. 205-243) is on screen translation. Once again, this is a detailed discussion of a phenomenon in which he is a leading international figure. He covers in detail the main facets of screen translation, most notably subtitling, including his own concept of 'diagonal translation' (p. 210), which moves from source-language speech to target-language writing. The chapter includes an interesting case study showing changes in subtitling speeds and techniques over the years (p. 233), a curious attempt to evaluate types of production according to 'mediapolitical qualities' and a thought-provoking 'postscript on methodology in translation research' (p. 244 ) that will be useful for research students. One of the recommendations is for the revisiting and replication of some of the empirical studies from the past to see whether contemporary settings, analytical techniques, etc. overturn some of the long-held conceptions of translation.

Finally, Ida Klitgård's chapter on literary translation applies Nord's framework for textual analysis to a particular case study, an extract from A.S. Byatt's Possession: A Romance, translated by students and compared with the published translation. This is a valuable exercise, and just the kind of analysis that can help students develop their skills. However, the student translations come from exam settings in which they were not allowed to look at the internet. This is somewhat restricting, since the ability to search for, find and evaluate parallel texts and potential translation equivalents is such a key translation skill. This is also not the only point at which the text appears in need of updating: for instance, the most recent readings on 'ethics' (p. 113) are from 2001, translation studies is described as being 'probably still in the initial phases of establishing itself as a discipline in its own right' (p. 133) and there is very little reference to the practical use of the internet, Computer-Assisted Translation tools, etcetera.

Nevertheless, the book is a valuable addition to the literature and a useful merging of theory and practical exercise. At the very beginning (p. 11), the three authors state that '[o]ur discussions focus on the reality of professional translation between Danish and English, but it is our hope that these discussions will also interest some international readers'. They should rest confident that Understanding Translation will certainly be of interest to an international audience and I foresee it inspiring teachers of translation and translation studies in many other countries.

Jeremy Munday 
